\title{
REMOTE HEMORRHAGE FROM THE SITE OF CRANIOTOMY
}

\author{
José Alberto Landeiro', Marlo Steiner Flores², Mário Alberto Lapenta², \\ Alexandre C. Galdino³, Bruno C.R. Lázaro ${ }^{3}$
}

\begin{abstract}
Postoperative intracranial hemorrhage is a serious and sometimes a fatal neurosurgical complication. Hemorrhage occurring at regions remote from the site of intracranial operations comprises an uncommon affection, most ignored by the assistant physicians. It bares a still incomprehensive pathophysiology, despite several theories trying to explain it. Looks like a common sense that the presence of the remote site hemorrhage cannot be related to concomitant presence of hypertension, coagulopathy or undiscovered lesions. We report three cases of postoperative hemorrhages occurring in a remote site of supratentorial craniotomies, two patients presented cavernous sinus meningeoma and one patient was submitted to intracranial vascular surgery.
\end{abstract}

KEY WORDS: remote site hemorrhage, craniotomy, postoperative hemorrhage.

\section{Hemorragia à distância da área da craniotomia}

RESUMO - Hemorragia intracraniana de ocorrência em pós-operatório é grave complicação das cirurgias intracranianas. $\mathrm{O}$ aparecimento de foco hemorrágico em regiões distantes ao sítio operatório original é considerado incomum, e muitas vezes ignorado pelos médicos assistentes. A fisiopatologia envolvida no processo não é de todo compreendida, apesar das diversas teorias já propostas. São apresentados três casos de hemorragia á distancia da área cirúrgica, no pós-operatório de dois pacientes portadores de meningeoma do seio cavernoso e de um submetido à clipagem de aneurisma intracraniano.

PALAVRAS-CHAVE: craniotomia, hemorragia no pós-operatório.

One of the major complications of craniotomy and the fearing of most surgeons is hemorrhage. Postoperatively hemorrhages usually occur at the site of the operation but surprisingly it can be presented in sites remote from the original surgical access as epidural, subdural, or intracerebral hemorrhage. Although there are few reports in the literature sometimes characterized as an incidental finding, remote site hemorrhage generally bares significant morbidity and mortality.

Nowadays, with the facility of images methods such as computer tomography scan (CT) and magnetic resonance images (MRI), remote site hemorrage plays a new role as a nosological entity in the chapter of neurosurgical complications. Despite of few previous reports, remote site hemorrhage can be appreciated as an independent pathology. We report 3 cases of remote hemorrhage from the site of craniotomy.

\section{CASES}

Case 1 - A 45-year old woman presented headaches and neck stiffness, evaluating worsening of the symptoms leading into a coma. Cerebral angiography was performed revealing a ruptured aneurysm of the anterior communicant artery. Surgical treatment of the aneurysm via the classic pterional approach was performed. After surgery, the patient was initially somewhat slow to awaken, and when she was fully awake, the neurological exam revealed a right cerebellar syndrome. Brain CT scan was obtained, revealing a small intraparenchymal cerebellar hemorrhage located at the right hemisphere. There were no signs of obstructive hydrocephalus or other associated lesions. The patient was investigated in order to access the possible causes of the cerebellar hemorrhage, but any alterations of the blood pressure or coagulopathy were found. There was no report of important surgical manipulation on the adjacent cerebral parenchyma. She was cared in a conservative manner, being discharged of the hospital shortly afterwards presenting minimal symptoms.

${ }^{1}$ M.D., PhD. Head of Neurosurgical Clinic, Hospital da Força Aérea do Galeão, Rio de Janeiro RJ, Brazil (HFAG), Neurosurgeon of Neurosurgical Department, Hospital Universitário Antonio Pedro, Universidade Federal Fluminense, Niterói RJ, Brazil (UFF); ${ }^{2} \mathrm{M} . D$. Neurosurgeon, HFAG; ${ }^{3}$ Residents in Neurosurgery, HFAG

Received 19 December 2003, received in final form 20 April 2004. Accepted 2 May 2004.

Dr. José Alberto Landeiro - Avenida Monsenhor Ascâneo 591/202 - 22621-060 Rio de Janeiro RJ - Brasil. E-mail: jlandeiro@aol.com 


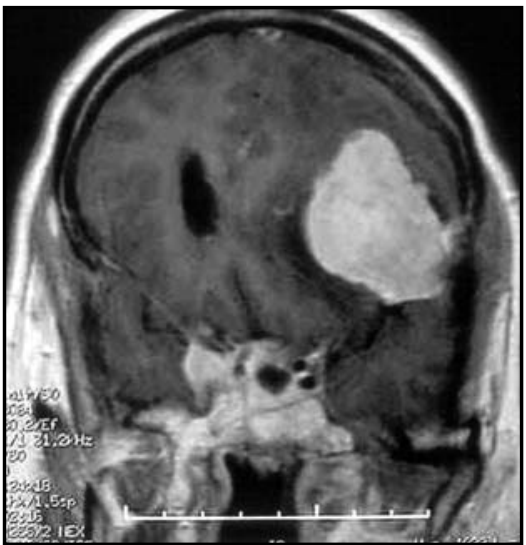

Fig 1. MR showing a volumous meningioma on the left side and mass effect. On the right side, a cavernous sinus tumour in a patient with trigeminal neuralgia.

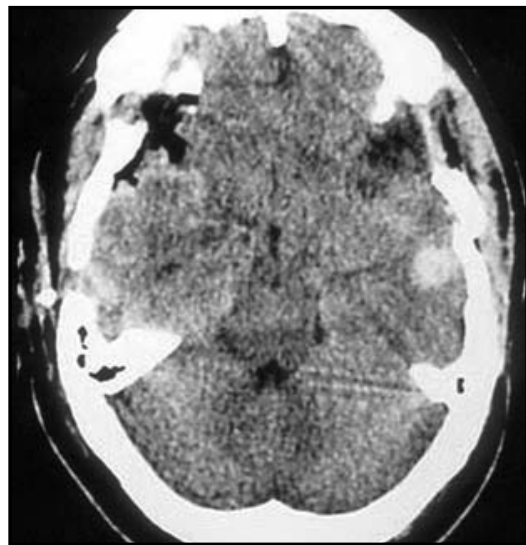

Fig 2. Immediatelly postoperative CT view showing a left side temporoparietal hematoma.

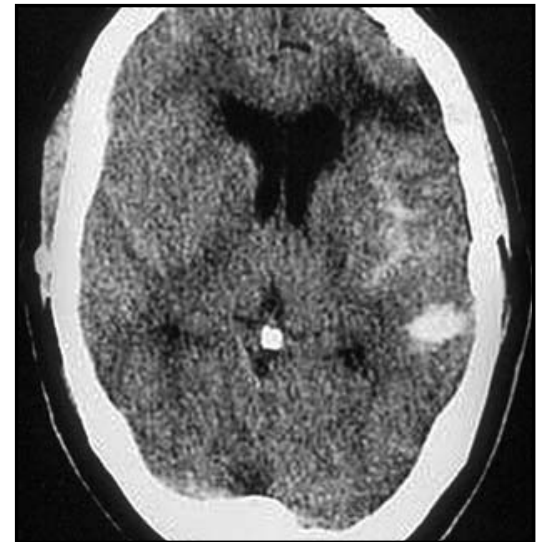

Fig 3. A CT scan reveals a subaracnoid hemorrhage in the same patient.

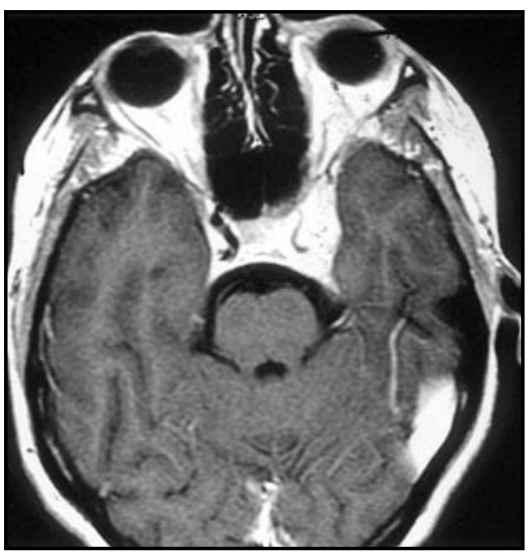

Fig 4. MRI T1, weigthed image with gadolinium enhancement showing a left holocavernous sinus meningioma. Note the involvement of the internal carotid artery.

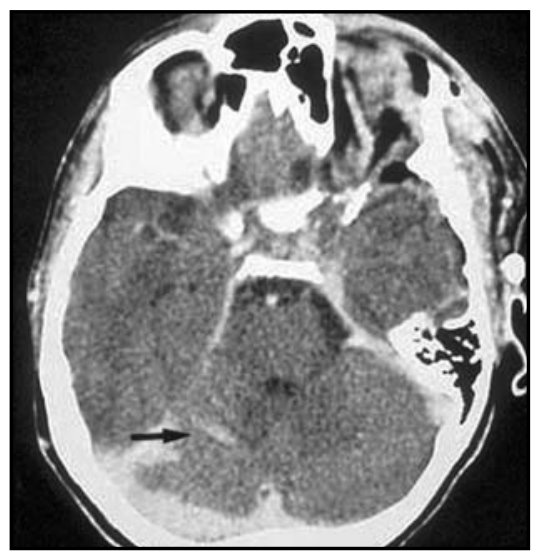

Fig 5. Postoperative CT scan reveals a small superficial cerebellar hemorrhage on the right side.

finding. The patient have had an uneventful clinical course, presenting a good outcome (Figs $1,2,3$ )

Case 3 - A 42-year-old woman with a meningioma in the left cavernous sinus was submitted to FOZ approach. Postoperatively, the patient presented headache, oculomotor palsy and lethargy. Brain CT performed on the next day showed an adequate ressection of the tumor with the presence of frontal pneumocephalus bellow the site of craniotomy and a small hematoma placed on the tentorial surface of the cerebellum. No mass effects were visualized on the posterior fossa, but the frontal pneumocephalus was associated to displacement of the frontal lobe. She was submmited to a pneumochephalus drainage, with the cerebellar lesion cared in a conservative fashion. The patient had a successful post operative course (Figs 4,5). 


\section{DISCUSSION}

Postoperative hemorrhage is a well known but serious complication of intracranial procedures and usually occurs at the site of the operation. Remote cerebellar hemorrhage ( $\mathrm{RCH}$ ) occurring after supratentorial craniotomy is the most commonly described pattern of remote hemorrhage $\mathrm{e}^{1-6}$ and may occasionally cause significant neurological morbidity or even death. Mortality may reach $25 \%$ of the cases ${ }^{1}$. Most of the cases described occurred within hours after the surgery, sometimes immediately afterwards, suggesting that most of these hemorrhages develop during or soon after surgery $^{2,7}$. The findings suggest that this clinical picture is unrelated to age, previous arterial hypertension, inherent or induced coagulopathies, type of primary underlying lesion, intraoperative positioning of the pacients or type of anesthesia ${ }^{8}$.

The loss of substantial CSF volume during surgery must play a central role in the pathophysiological development of remote cerebellar hemorrhage ${ }^{1,2,4,7-9}$. Suction of the CSF may cause intracranial hypotension. Further reduction of intracranial pressure leads to an increased transluminal venous pressure ${ }^{2,7,10,11}$.

A growing consensus suggests that $\mathrm{RCH}$ is likely to be a manifestation of cerebellar venous infarction and hemorrhage. Typical location, in the superior cerebellar and vermian cortex, corresponds to the territory drained by superior cerebellar veins ${ }^{3}$. The timing for the appearance of the symptoms and apparent "blossoming" on CT in the first 24 hours after surgery are not specific but are consistent with evolution of venous hemorrhage ${ }^{2}$. With regard to neoplastic lesions, meningiomas have been described to be most frequently complicated by hemorrhagic postoperative manifestations, probably because of abnormal hyperfibrinolysis, but not directly related to remote hemorrhage ${ }^{1,12}$.

In our cases, all patients were women, consisting in 2 cases of brain tumor (meningeoma) and 1 consisted of ruptured aneurysm. One patient has presented previous arterial hypertension, but none of the hemorrhages had a typical appearance of hipertensive hemorrhage. Coagulation parameters of these three patients were normal, both pre- and postoperatively. All patients were operated in supine position.

Cerebellar remote hemorrhage is an under-recognized complication after supratentorial neurosurgical procedures, specially those involving the opening of CSF cisterns or the ventricular system ${ }^{1,2,7}$.

Although the occurrence of $\mathrm{RCH}$ is associated with some risk of death or major morbidity, in most cases a benign course is exhibited. Cerebellar "sag" as a result of CSF volume loss, causing transient occlusion of superior bridging cerebellar veins and consequent hemorrhagic venous infarction, is the most likely cause of $\mathrm{RCH}^{1,2}$.

Not one single presurgical or surgical factor can reliably predict the occurrence of cerebellar hemorrhage after supratentorial craniotomy or remote hemorrhages at all, and the etiology of this entity still remains unclear. The most important keys to minimize the hazardous sequelae are to be aware of this potential complication, attempt to a precocious diagnosis and to provide prompt treatment in all cases.

\section{REFERENCES}

1. Marquardt G, Setzer M, Schick U, Seifert V. Cerebellar hemorrhage after supratentorial craniotomy. Surg Neurol 2002;57:241-251.

2. Friedman M, Piepgras PG, Duke DA, et al. Remote cerebellar hemorrhage after supratentorial surgery. Neurosurgery 2201;49:1327-1340.

3. Konig A, Laas R, Hermann HD. Cerebellar hemorrhage as a complication after supratentorial craniotomy. Acta Neurochir (Wien) 1987;88:104-108.

4. Cloft HJ , Matsumoto JA, Lanzino G, Cail WS. Posterior fossa hemorrhage after supratentorial surgery. Am J Neuroradiol 1997;18:1573-1580.

5. Honegger J, Zetner J, Spreer J, Carmona H, Shulze-Bohage A. Cerebellar hemorrhage arising postoperatively as a complication of supratentorial surgery: a retrospective study. J Neurosurg 2002;96:248-254.

6. Lefranc F, De Witte O, David P, Brotchi J. Cerebellar hemorrhage complicating a supratentorial craniotomy: a case report and review of the literature. Neurochirurgie 2000;46:395-397.

7. Tomii M, Nakajima M, Ikeuchi S, Ogawa T, Abe T. Infratentorial hemorrhage following supratentorial surgery. No Shinkei Geka 1999;27: 921-925.

8. Brisman MH, Bederson JG, Sen CN, Germano IM, Moore F, Post KD. Intracerebral hemorrhage occurring remote from the craniotomy site. Neurosurgery 1996;39:1114-1121.

9. Kuroda R, Nakatami J, Akai F, et al. Remote subarachnoid hemorrhage in the posterior fossa following supratentorial surgery: clinical observation of six cases. Acta Neurochir (Wien) 1994;12:158-165.

10. Yoshida S, Yonekawa Y, Yamashita K, Ihara I, Morooka Y. Cerebellar hemorrhage after supratentorial craniotomy: report of three cases. Neurol Med Chir (Tokyo) 1999;30:738-743.

11 Koller M, Ortler M, Langmayr J, Twerdy K. Posterior-fossa hemorrhage after supratentorial surgery: report of three cases and review of the literature. Acta Neurochir (Wien) 1999;141:587-592.

12. Kalfas IH, Little JR. Postoperative hemorrhage: a survey of 4992 intracranial procedures. Neurosurgery 1998;23:343-357. 